\title{
Effect of inhaled thiorphan, a neutral endopeptidase inhibitor, on the bronchodilator response to inhaled atrial natriuretic peptide (ANP)
}

\author{
Robert M Angus, Evelyn A Millar, George W Chalmers, Neil C Thomson
}

\begin{abstract}
Background - The hormone atrial natriuretic peptide (ANP) causes bronchodilation and partially protects against direct and indirect bronchial challenges. Both in vitro and in vivo studies have found that the protective effect of ANP against bronchoconstriction is enhanced by inhibition of the enzyme neutral endopeptidase (NEP). It was hypothesised that pretreatment with thiorphan, an NEP inhibitor, might enhance the bronchodilator response to inhaled ANP.

Methods - In a randomised double blind placebo controlled crossover study, six asthmatic patients (one woman) of mean (SD) age $47.3(3.8)$ years and forced expiratory volume in one second $\left(F E V_{1}\right) 1.91$ $(0.42) 1,55(3.8) \%$ predicted, were studied. All were shown at screening to have at least a $25 \%$ improvement in $\mathrm{FEV}_{1}$ to inhaled salbutamol. On five study visits the patients received either thiorphan $1 \mathrm{mg}$ (in $2 \mathrm{ml}$ ) followed by ANP $5 \mathrm{mg}$ or placebo (saline), or placebo (saline) followed by ANP (5 mg), placebo or salbutamol $5 \mathrm{mg}$. Spirometric parameters were measured after each inhalation and thereafter for the next two hours.
\end{abstract}

Results - ANP alone caused a bronchodilator response up to 15 minutes when compared with placebo or thiorphan alone with a mean (SE) change in $\mathrm{FEV}_{1}$ of 16.8 $(8 \cdot 1) \%$ and $16 \cdot 1(6 \cdot 8) \%$ at 10 and 15 minutes from baseline, respectively. Prior inhalation of thiorphan prolonged the duration of the bronchodilator effect of ANP up to 60 minutes with a mean (SE) change in $\mathrm{FEV}_{1}$ of $23.1(3.4) \%$ at 60 minutes. There was no difference in the maximum degree of bronchodilation following the administration of ANP alone compared with the combination of thiorphan and ANP. The degree and duration of the bronchodilator response produced by ANP, or the combination of the NEP inhibitor and ANP, were less than that produced by salbutamol.

Conclusions - These results confirm that, at least in part, the bronchodilator response to inhaled ANP is modulated by NEP. Analogues of ANP which are stable to NEP may have greater bronchodilator activity than ANP in the treatment of asthma.

(Thorax 1996;51:71-74)
Keywords: neutral endopeptidase inhibitor (NEP), thiorphan, atrial natriuretic peptide (ANP), bronchodilator, asthma.

Atrial natriuretic peptide (ANP), when administered by intravenous infusion to asthmatic patients, causes a similar degree of bronchodilation to that produced by infused and nebulised salbutamol. ${ }^{1-3}$ ANP also protects against both direct and indirect bronchial challenges. ${ }^{45}$ It is not, however, orally bioavailable and inhalational studies thus far have shown only a modest effect on airway tone and reactivitiy. ${ }^{6-8}$

The relatively small effects of ANP when given by the inhaled route suggest that it may be being degraded within the airways. ANP is cleaved enzymatically by neutral endopeptidase (NEP); this enzyme is found in airway epithelium and it is of note that concentrations of NEP in the airways are higher than those found in the lung vasculature or parenchyma. ${ }^{9}$ In vitro we have found that the addition of phosphoramidon, whose actions include the inhibition of NEP, enhances the relaxant and protective effects of ANP on airway smooth muscle. ${ }^{10}$ In vivo the protective effect of ANP against histamine-induced bronchoconstriction is enhanced by pretreatment with thiorphan, ${ }^{11}$ a potent inhibitor of NEP. ${ }^{12}$ An alternative approach to harnessing the bronchodilator potential of inhaled ANP on the airway might therefore be to inhibit NEP locally and so prevent the breakdown of exogenously administered ANP.

The present study was designed to determine the effect of preinhalation of thiorphan on the bronchodilator response to inhaled ANP in asthmatic patients.

\section{Methods}

PATIENTS

Six asthmatic patients (one woman) of mean (SD) age $47.3(3.8)$ years and forced expiratory volume in one second $\left(\mathrm{FEV}_{1}\right)$ of $1.91(0.42) 1$, $55(3.8) \%$ predicted, were studied (table 1 ). Asthma was defined according to ATS criteria. ${ }^{13}$ Due to the high cost of ANP, patient numbers were limited to six, all of whom had shown an improvement in $\mathrm{FEV}_{1}$ to inhaled salbutamol of at least $25 \%$ at a screening visit. All were taking short acting $\beta_{2}$ agonists and inhaled corticosteroids. Patients had to be stable for at least six weeks before entering the study and to have had no alteration in their

5 June 1995

Revised version received

14 August 1995

Accepted for publication

7 September 1995 
Table 1 Patient characteristics

\begin{tabular}{|c|c|c|c|c|}
\hline \multirow{2}{*}{$\begin{array}{l}\text { Patient } \\
\text { no. }\end{array}$} & \multirow{2}{*}{$\begin{array}{l}\text { Age } \\
\text { (years) }\end{array}$} & \multicolumn{2}{|c|}{ Forced expiratory volume in one second (FEV ) } & \multirow[t]{2}{*}{ Therapy } \\
\hline & & Absolute value (l) & \% Predicted & \\
\hline $\begin{array}{l}1 \\
2 \\
3 \\
4 \\
5 \\
6\end{array}$ & $\begin{array}{l}53 \\
40 \\
37 \\
40 \\
55 \\
59\end{array}$ & $\begin{array}{l}2.79 \\
1.29 \\
3.64 \\
1.68 \\
0.90 \\
1.46\end{array}$ & $\begin{array}{l}74 \\
39 \\
91 \\
60 \\
27 \\
40\end{array}$ & $\begin{array}{l}\text { S,B,T } \\
\text { S,B,P } \\
\text { S,B,Salm } \\
\text { S,B } \\
\text { S,B,P } \\
\text { S,B,P }\end{array}$ \\
\hline Mean (SD) & $47 \cdot 3(3 \cdot 8)$ & $1.91(0.42)$ & $55(3 \cdot 8)$ & \\
\hline
\end{tabular}

$\mathrm{B}=$ inhaled beclomethasone dipropionate $>1000 \mu \mathrm{g} ; \mathrm{S}=$ inhaled salbutamol; Salm $=$ inhaled salmeterol; $\mathrm{P}=$ prednisolone; $\mathrm{T}=$ theophylline.

regular treatment. The study had the approval of the Glasgow West ethical committee and informed written consent was obtained from each patient.

\section{STUDY DESIGN}

A randomised double blind placebo controlled study design was employed. Before each study day patients were asked to withhold short acting $\beta_{2}$ agonists for eight hours, long acting $\beta_{2}$ agonists for at least 15 hours, and theophyllines for 24 hours. Inhaled and oral corticosteroids were continued unaltered. If the $\mathrm{FEV}_{1}$ was within $15 \%$ of the baseline on the screening day the study proceeded on that day. Patients were asked to sit and an intravenous cannula was inserted for blood sampling in the antecubital vein. Patients remained seated throughout the study while spirometric tests were performed. Before dosing, heart rate and blood pressure were measured. Blood pressure and pulse were monitored using a semiautomatic sphygmomanometer. On five separate study visits they received an initial inhalation of either thiorphan (Sigma Chemical Company, Poole, Dorset, UK), $1 \mathrm{mg}$ (in $2 \mathrm{ml}$ ), followed by ANP $5 \mathrm{mg}$ or placebo (saline), or an initial inhalation of placebo (saline) followed by ANP ( $5 \mathrm{mg}$ ) ( $\alpha$-human ANP 28 amino acid; UCB, Pharma, Brussels, Belgium), placebo, or salbutamol $5 \mathrm{mg}$. All inhalations were administered by a Sidestream nebuliser with a Mizer aerosol conservation device driven by a Porta-Neb compressor (Medic-Aid, Pagham, Sussex, UK). The residual volume after nebulisation was $0.6 \mathrm{ml}$. Spirometric values were measured immediately after each inhalation and then followed for two hours after the second inhalation at times $0,5,10,15,30,60,90$, and 120 minutes. The $\mathrm{FEV}_{1}$ (best of three) was measured using a dry wedge spirometer (Vitalograph S; Vitalograph, Buckingham, UK). Blood $(20 \mathrm{ml})$ was sampled for drug and hormone levels (ANP, cyclic guanosine monophosphate (cGMP), and catecholamines) at $0,5,10,15$, $30,60,90$, and 120 minutes.

\section{HORMONE ASSAYS}

$A N P$

Venous blood $(10 \mathrm{ml})$ was collected into potassium EDTA tubes containing $1000 \mathrm{IU}$ aprotinin (Bayer, Newbury, UK), stored on ice and spun within two hours. Plasma was stored at $-20^{\circ} \mathrm{C}$ and ANP was later measured by radio- immunoassay following pre-extraction with C18 reverse phase columns (Sep-Pak; Waters, Milford, Massachusetts, USA). Both interassay and intra-assay variation were $\leqslant 8 \%{ }^{14}$

\section{cGMP}

Venous blood $(5 \mathrm{ml})$ was collected into lithium heparin tubes, stored on ice, and spun within two hours. Cyclic GMP was later measured by radioimmunoassay after pre-extraction of plasma onto Amprep minicolumns (Amersham International, Aylesbury, Buckinghamshire, UK) [RPN1918]. ${ }^{15}$

\section{Catecholamines}

Venous blood $(5 \mathrm{ml})$ was collected into lithium heparin tubes, stored on ice, and spun within two hours. Plasma adrenaline and noradrenaline levels were measured by reverse phase high performance chromatography and electrochemical detection was carried out after extraction from plasma using activated alumina. The coefficient of variation for this assay is $<10 \%$. $^{16}$

\section{DATA ANALYSIS}

Changes in $\mathrm{FEV}_{1}$ (\% change), pulse, and blood pressure were compared using analysis of variance of repeated measures and Dunnett's test for correction. This was performed on an Apple Macintosh LC personal computer using the Statview software package. A p value of $<0.05$ was taken as significant.

\section{Results}

Baseline $\mathrm{FEV}_{1}$ was similar on all visits. There were no significant changes in $\mathrm{FEV}_{1}$ following thiorphan or placebo (table 2).

ANP alone caused a significant bronchodilator response up to 15 minutes when compared with placebo or thiorphan alone (mean (SE) change in $\mathrm{FEV}_{1}$ of $16 \cdot 8(8 \cdot 1) \%$ and $16 \cdot 1$ $(6.8) \%$ from baseline at 10 and 15 minutes, respectively; fig 1). Prior inhalation of thiorphan significantly prolonged the duration of the bronchodilator effect of ANP up to 60 minutes (mean (SE) change in $\mathrm{FEV}_{1}$ of $23 \cdot 1$ $(3.4) \%)$. There was no difference in the maximum degree of bronchodilation following the administration of ANP alone compared with the combination of thiorphan and ANP. With both ANP and the combination of the NEP inhibitor and ANP the degree of bronchodilation was significantly less than that produced by salbutamol which was maximal at one hour (mean (SE) change in $\mathrm{FEV}_{1}$ of $53(10.5) \%$ ) and maintained at two hours (fig 1).

ANP and cGMP levels were significantly raised at both visits when ANP was administered (figs 2 and 3). Maximal mean (SE) levels of ANP of $13.2(4.5) \mathrm{pmol} / 1$ and cGMP of $11(1.8) \mathrm{pmol} / 1$ were achieved when the inhalation of ANP was preceded by placebo compared with an ANP level of $39(13.5) \mathrm{pmol} / 1$ and a cGMP level of $28(5 \cdot 8) \mathrm{pmol} / 1$ with thiorphan pretreatment. The significantly 
Table 2 Effect of inhalation of thiorphan and ANP on baseline mean (SE) forced expiratory volume in one second $(F E V)$ in litres

\begin{tabular}{llllll}
\hline & $P P$ & $P A$ & $T P$ & $T A$ & $P S$ \\
\hline Baseline & $2 \cdot 19(0 \cdot 4)$ & $2 \cdot 06(0 \cdot 4)$ & $2 \cdot 10(0 \cdot 4)$ & $2 \cdot 12(0 \cdot 4)$ & $2 \cdot 04(0 \cdot 4)$ \\
Immediately after 1st inhalation & $2 \cdot 03(0 \cdot 4)$ & $2 \cdot 09(0 \cdot 4)$ & $2 \cdot 02(0 \cdot 5)$ & $2 \cdot 21(0 \cdot 4)$ & $1 \cdot 97(0 \cdot 3)$ \\
Immediately after 2nd inhalation & $2 \cdot 16(0 \cdot 4)$ & $2 \cdot 07(0.4)$ & $2 \cdot 26(0.5)$ & $2 \cdot 49(0.5)$ & $2 \cdot 45(0.5) *$ \\
\hline
\end{tabular}

$\mathrm{PP}=$ placebo + placebo; $\mathrm{PA}=$ placebo $+\mathrm{ANP} ; \mathrm{TP}=$ thiorphan + placebo; $\mathrm{TA}=$ thiorphan $+\mathrm{ANP} ; \mathrm{PS}=$ placebo + salbutamol. ${ }^{*} \mathrm{p}<0.05$ when compared with baseline.

higher ANP and cGMP levels on the thiorphan/ ANP treatment days when compared with placebo/ANP lasted up to 15 and 30 minutes, respectively (figs 2 and 3 ). Thiorphan itself did not cause a significant change in ANP or cGMP levels. There were no significant changes in catecholamines on any visit (data not shown).

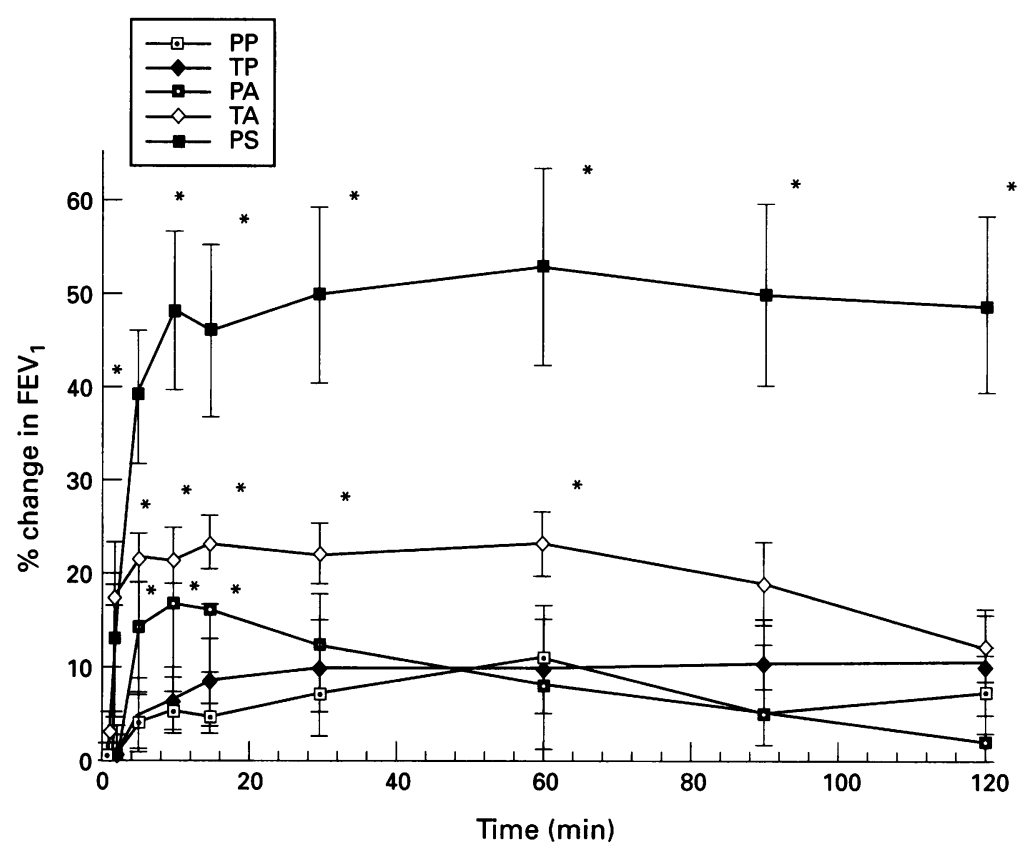

Figure 1 Mean (SE) change in FEV, (\%) following placebo, atrial natriuretic peptide (ANP), thiorphan, and thiorphan plus ANP and salbutamol in six asthmatic patients. $P P=$ placebo + placebo $P A=$ placebo $+A N P ; T P=$ thiorphan + placebo $T A=$ thiorphan + $A N P ; P S=$ placebo + salbutamol. ${ }^{*} p<0.05$ compared with $P P$ and $T P$.

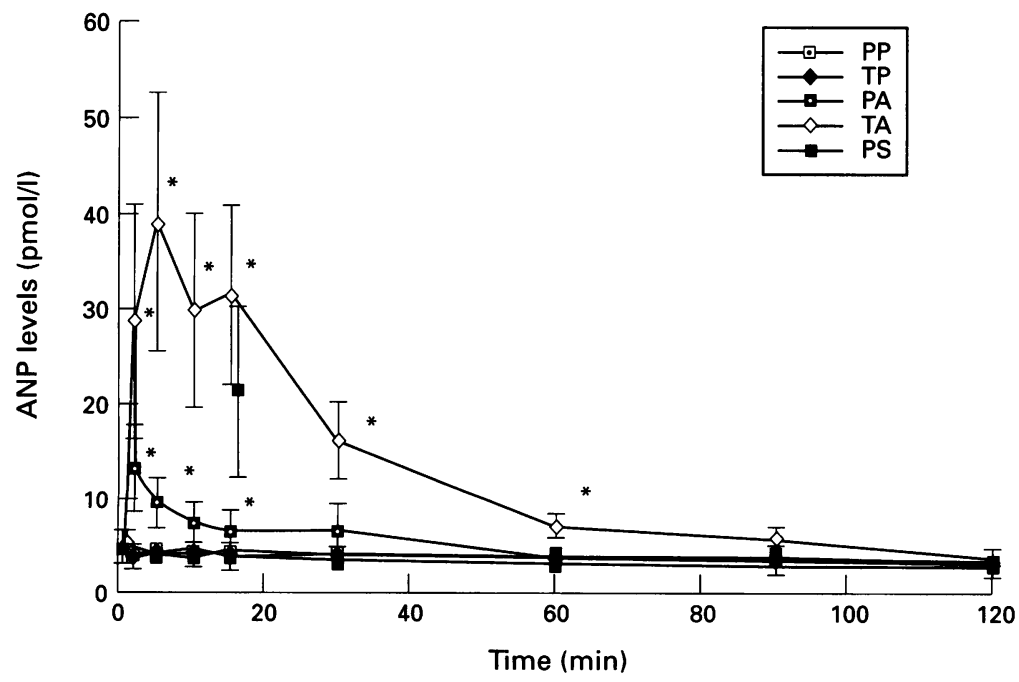

Figure 2 Mean (SE) change in plasma atrial natriuretic peptide (ANP) levels following inhalation of placebo, ANP, thiorphan, and thiorphan plus ANP and salbutamol in six asthmatic patients. $P P=$ placebo + placebo; $P A=$ placebo $+A N P ; T P=$ thiorphan + placebo; $T A=$ thiorphan $+A N P ; P S=$ placebo + salbutamol. ${ }^{*} p<0.05$ compared with $P P$ and $T P$.
There were no measured changes in pulse or blood pressure on placebo or active treatment days after thiorphan, ANP, or the combination of ANP and thiorphan. A significant tachycardia was noted with salbutamol (data not shown).

\section{Discussion}

These results confirm our previous observation that ANP in high doses can produce a significant bronchodilator response when given by inhalation. ${ }^{8}$ They also demonstrate that prior inhalation of the NEP inhibitor thiorphan prolongs the bronchodilator effect of inhaled ANP in asthmatic patients. In a previous study we have found in vitro that pretreatment with the NEP inhibitor phosphoramidon enhances the ability of ANP to relax preconstricted bronchial smooth muscle and also to enhance the protectant effect of ANP against methacholineinduced contraction. ${ }^{9}$ We have also previously found that in vivo prior inhalation with thiorphan can enhance the protectant effect of ANP against histamine-induced bronchoconstriction. ${ }^{10}$ In this study we have found that pretreatment with thiorphan allows higher levels of circulating ANP and cGMP to be attained, and that this elevation is prolonged by thiorphan. Our results would therefore confirm that airway NEP is important, at least in part, in modulating the effect of inhaled ANP in humans.

It should be noted, however, that there was only partial bronchodilation when the response to ANP was compared with that to salbutamol. In the studies of infused ANP the degree of bronchodilation was very similar. ${ }^{1-3}$ Several factors may explain this. Firstly, although thiorphan is a potent inhibitor of NEP we have no direct measure of inhibition of the enzyme and it could easily be envisaged that this may only be partial, therefore affording only a degree of protection against ANP breakdown. Secondly, there is some evidence in pulmonary tissue that inactivation of ANP may occur following binding to a clearance receptor and that this effect is not inhibited by thiorphan. ${ }^{17}$ Thirdly, although ANP receptors have been demonstrated in the lungs of other species, these have not been sought in humans, and the precise site of action of the ANP in the lung is not certain. Fourthly, there are no dose response studies of the airway response to ANP by the inhalational route; practicalities of solubility, time of nebulisation, and expense limited us to the $5 \mathrm{mg}$ dose administered and to the small sample size. It is possible that higher doses perhaps given by the aerosol route - would have a larger effect. Certainly the achieved 


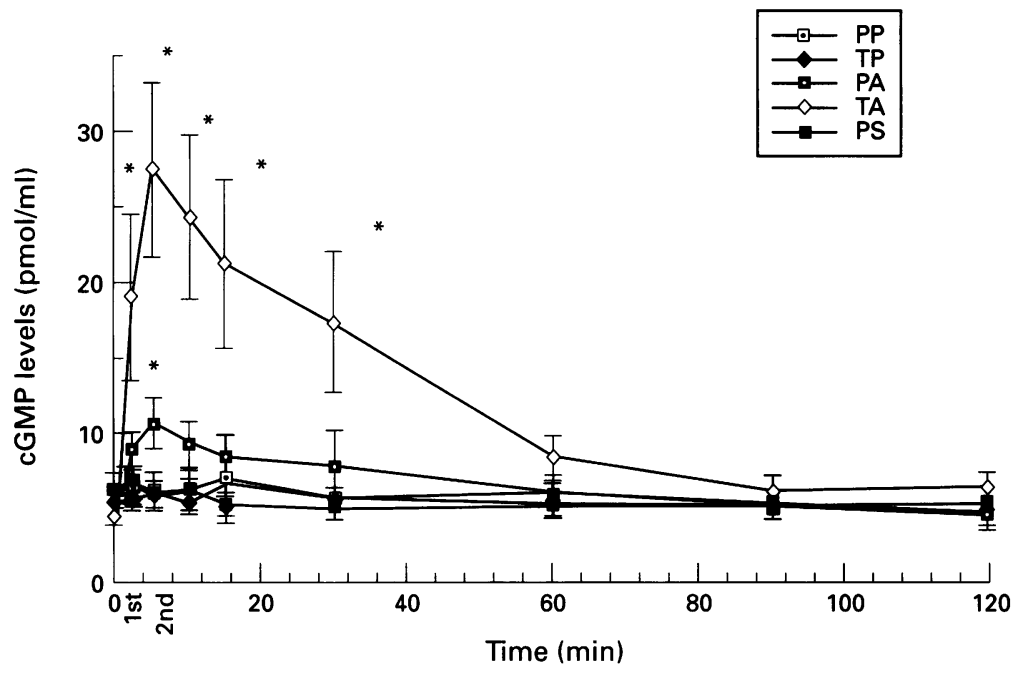

Figure 3 Mean (SE) change in plasma cyclic guanosine monophosphate (cGMP) levels following inhalation of placebo, atrial natriuretic peptide $(A N P)$, thiorphan, and thiorphan plus $A N P$ and salbutamol in six asthmatic patients. $P P=$ placebo + placebo; $P A=$ placebo $+A N P ; T P=$ thiorphan + placebo; $T A=$ thiorphan $+A N P ; P S=$ placebo + salbutamol. ${ }^{*} p<0.05$ compared with $P P$.

circulating levels of ANP and cGMP are considerably less than was seen in our infused studies of ANP. With higher systemic levels of ANP, however, there is a possibility of significant cardiovascular effects, ${ }^{3}$ although no such effects were noted in the present study. Similarly, there was no alteration in catecholamine levels to suggest that the bronchodilator effect was mediated indirectly due to the release of adrenaline.

It may also be of importance that, in addition to ANP, NEP cleaves various active peptides including bradykinin and tachykinins such as neurokinin $A$ and substance P. $^{18}$ Several of these mediators have bronchoconstrictor properties $^{1819}$ and it might be speculated that inhibition of NEP would increase local levels of these agents, potentially antagonising any bronchodilator effect of ANP and cGMP. Against this, however, is our previous observation that acute administration of the oral NEP inhibitor candoxatril does not alter bronchomotor tone or non-specific reactivity, and the observation here that thiorphan alone does not cause a fall in $\mathrm{FEV}_{1}{ }^{20}$

ANP given intravenously is a potent bronchodilator, but when administered by inhalation it appears to be less effective. This study shows that ANP can cause significant bronchodilation when given by inhalation and that, at least in part, this is modulated by NEP. ANP is attractive as a possible therapeutic agent in airways disease because of its different intracellular mode of action and the potential of interactive effects with current bronchodilator therapies. ${ }^{21}$ At present, however, it remains that any likely clinical application of ANP in asthma would be limited to the intravenous route.
Nevertheless, there remains the prospect that it may be possible to exploit the bronchodilator effects of inhaled agents acting on the particulate guanylyl cyclase pathway; one possibility for this would be the inhalation of ANP analogues stable to the clearance of the peptide in the lung.

The authors wish to thank Ms Wendy Fallon and Ms Catherine Glen for their help with drug preparation and the blinding of the study. They also wish to thank Dr JJ Morton for his help with hormone analysis. ANP was kindly supplied by UCB wharma.

RMA was supported by the British Lung Foundation.

1 Hulks G, Jardine A, Connell JMC, Thomson NC. Bronchodilator effect of atrial natriuretic peptide in asthma. BMF 1989;299:1081-2.

2 Chanez P, Mann C, Bousquet J, Chabrier PE, Godard P, Braquet $\mathrm{P}$, et al. Atrial natriuretic factor (ANF) is a potent bronchodilator in asthma. $\mathcal{F}$ Allergy Clin Immunol 1990; 86:321-4.

3 Angus RM, McCallum MJA, Hulks G, Thomson NC. The bronchodilator, cardiovascular and cyclic guanyly (cGMP) response to high dose infused atrial natriuretic peptide in asthma. Am Rev Respir Dis 1993;147:1122-5.

4 Hulks G, Jardine A, Connell JMC, Thomson NC. Influence of elevated plasma levels of atrial natriuretic factor on bronchial reactivity in asthma. Am Rev Respir Dis 1991, 143:778-82.

5 McAlpine LG, Hulks G, Thomson NC. The effect of an intravenous infusion of atrial natriuretic factor on fog induced bronchsonstriction in patients with asthma $A m$ Rev Respir Dis 1992;146:912-5.

6 Hulks G, Thomson NC. Inhaled atrial natriuretic peptide and asthmatic airways. BMF 1992;304:1156.

7 Angus RM, MacCallum MJA, Thomson NC. Effect of inhaled atrial natriuretic peptide on methacholine induced bronchoconstriction in asthma. Clin Exp Allergy 1994;24: bronch $784-8$.

8 Hulks G, Thomson NC. High dose inhaled atrial natriuretic peptide is a bronchodilator in asthmatic subjects. Eur Respir f 1994;7:1593-7.

9 Johnson AR, Ashton J, Schulz WW, Erdos EG. Neutra metalloendopeptidase in human lung tissue and cultured cells. Am Rev Respir Dis 1985;132:564-8.

10 Angus RM, Nally JE, Young LC, McCall R, McGrath JC, Thomson NC. Modulation of the effect of atrial natriuretic peptide in human and bovine bronchi by phosphoramidon. Clin Sci 1994;86:291-5.

11 Angus RM, Millar EA, Chalmers GW, Thomson NC. Effect of inhaled atrial natriuretic peptide and a neutral endopeptidase inhibitor on histamine-induced bronchoconstriction. Am f Respir Crit Care Med 1995;151:2003-5.

12 Roques BP, Fournie-Zaluski MC, Soroca E, Lecomte JM Malfroy B, Llorens C, et al. The enkephalinase inhibitor thiorphan shows antinociceptive activity in mice. Nature 1980;288:286-8.

13 American Thoracic Society. Standards for the diagnosis and care of patients with chronic obstructive pulmonary disease (COPD) and asthma. Am Rev Respir Dis 1987;136:225-44

14 Richards AM, Tonolo G, McIntyre GD, Leckie BJ, Robertson JIS. Radioimmunoassay for plasma alpha human natriuretic peptide: a comparison of direct and pre-exnatriuretic peptide: a comparison of direct and
tracted methods. $₹$ Hypertension $1987 ; 5: 227-36$.

15 Lyall F, Balmforth AJ, Morton JJ. Specific binding of atrial natriuretic peptide increases cyclic GMP levels in human astrocytoma cells. $\mathcal{F}$ Endrocrinol 1987;117:315-21.

16 Goldstein DS, Feuerstein G, Izzo JL Jr, Kopin IJ, Keiser HR. Validity and reliability of liquid chromatography with electrochemical detection for measuring plasma levels of norepinephrine and epinephrine in man. Life Sci 1981;28 467-75.

17 James S, Burnstock G. Atrial and brain natriuretic peptides sharing binding sites on cultural cells from the rat trachea. Cell Tissues Res 1991;265:555-65.

18 Erdos EG, Skidgel RA. Neutral endopeptidase 24.11 (enkephalinase) and related regulators of peptide hormones. FASEB $₹$ 1989;3:145-51.

19 Nadel JA. Neutral endopeptidase modulates neurogenic inflammation. Eur Respir $\mathcal{f} 1991 ; 4: 745-54$.

20 Angus RM, MacCallum MJA, Thomson NC. No effect on bronchomotor tone and histamine reactivity by the neutral endopeptidase inhibitor candoxatril in mild asthmatic patients. Eur Respir f 1994;7:1084-9.

21 Nally JE, Clayton RA, Thomson NC, McGrath JC. The interaction of human atrial natriuretic peptide (ANP) with salbutamol, sodium nitroprusside and isosorbide dinitrate in human smooth muscle. Br $\mathcal{P}$ Pharmacol 1994;113:1328 32 . 